\title{
Effects of Foxc1 and Oct4 genes regulating BMSCs transplantation on cardiomyocyte apoptosis after acute myocardial infarction in rats
}

\author{
Dongming $\mathrm{ZHANG}^{1}$, Shaoze WU ${ }^{1 *}$ (iD
}

\begin{abstract}
To investigate the effect of Foxc1 and Oct4 genes regulated by bone marrow mesenchymal stem cells (BMSCs) transplantation on cardiomyocyte apoptosis after acute myocardial infarction in rats. 180 healthy SD male rats were divided into 3 groups by random number table method, namely control group, acute myocardial infarction (AMI) group and BMSCs group. The rats were sacrificed 4 weeks after transplantation. The TUNEL method was used to detect the cardiomyocyte apoptosis index. The control group basically had no cardiomyocyte apoptosis, while the apoptosis indexes of AMI group $(0.67 \pm 0.14)$ was higher than that $(0.31 \pm 0.12)$ of BMSCs group $(\mathrm{P}<0.05)$. The OD value of Foxc1 and Oct4 protein in BMSCs group was higher than those in AMI group (all $\mathrm{P}<0.05$ ). BMSCs transplantation can reduce cardiomyocyte apoptosis after AMI in rats. The mechanism may be related to the up-regulation of Oct4 and Foxc1 protein expression.
\end{abstract}

Keywords: Foxc1; Oct4; bone marrow mesenchymal stem cell; apoptosis; acute myocardial infarction.

Practical application: Thereby inhibiting cardiomyocyte apoptosis and improving the function of the heart, while improving the prognosis of AMI.

\section{Introduction}

Bone marrow mesenchymal stem cells (BMSCs) are derived from bone marrow stromal stem cells and are a subset of cells found in mammalian bone marrow stromal cells with multiple differentiation potentials that differentiate into bone, cartilage, fat, nerve and myoblast (Xiong et al., 2020; Yamada et al., 2019). They not only have mechanical support for hematopoietic stem cells (HSC) in bone marrow, but also secrete various growth factors (such as IL-6, IL-11, LIF, M-CSF and SCF, etc.) to support hematopoiesis (Mahmoudian-Sani et al., 2019). The content of BMSCs in bone marrow is very low, accounting for only $0.001-0.01 \%$ of the content of bone marrow monocytes (Kamm et al., 2019; Mazdeh et al., 2018). It is a stem cell with strong self-renewal and multi-directional differentiation potential (Dudhia et al., 2015).

BMSCs are located in different microenvironments and can differentiate into the tissues and cells under the action of various transcription factors and cytoplasmic factors (Fujimori et al., 2019). For example, bone tissue can differentiate into osteoblasts and chondrocytes, blood can differentiate into red blood cells, and adipose tissue can differentiate into fat cells (Mahmoud et al., 2020; Dey et al., 2020). A large number of experiments have shown that the myocardial tissue microenvironment can induce differentiation of BMSCs (Chen et al., 2020; Omar et al., 2019; Wu et al., 2017; Zhang et al., 2015). Whether it is to inject BMSCs into the site of myocardial infarction (subepithelial injection, subendocardial injection, intravenous injection, etc.), or to culture BMSCs with myocardial cells, it can promote the differentiation of BMSCs into cardiomyocytes, and the electromechanical coupling of the two is well fused (Eldin et al., 2019; Lu et al., 2019). The number of BMSCs is not large, and it decreases with age (Majid et al., 2020; Sultan et al., 2021; Vidal et al., 2020). Therefore, we can expand in vitro to obtain more cells for research and treatment.

After acute myocardial infarction (AMI), myocardial cell apoptosis increases and can cause heart failure (Omar et al., 2019; Xie et al., 2019). How to inhibit myocardial cell apoptosis has become the key to the treatment of ischemic heart disease. In recent years, studies have suggested that bone marrow stem cell transplantation can treat certain cardiovascular diseases (Zhang et al., 2015; Xu et al., 2019; Su et al., 2017). The purpose of bone marrow stem cells in the treatment of myocardial infarction is to reverse the apoptosis of myocardial cells, but the specific mechanism of anti-apoptosis of BMSCs transplanted myocardial infarction disease is still unknown and needs further study. Therefore, this experiment aims to study the effect of rat bone marrow mesenchymal stem cell transplantation on Foxcl and Oct4 expression and their correlation, by exploring the effect mechanism of bone marrow mesenchymal stem cell transplantation on myocardial cell apoptosis after acute myocardial infarction in rats, it provides a theoretical basis for clinical application of bone marrow mesenchymal stem cell transplantation.

\section{Materials and methods}

\subsection{Research objects and groups}

180 healthy 4-week-old male SD rats (weight about $200 \mathrm{~g}$ ) were divided into 3 groups by random number table method, namely control group, AMI group and BMSCs group, 60 rats 
per group. For the AMI group and the BMSCs group, a model of myocardial infarction was established by ligating the anterior descending coronary artery, while the control group only opened the thoracic cavity without ligating the anterior descending coronary artery. 30 minutes after coronary artery ligation, BrdUlabeled BMSCs $100 \mu \mathrm{L}$ were injected into 4 different sites under the epicardium in the BMSCs group ischemia area. The AMI group and the control group were injected with the same dose of normal saline. The detection index was rats sacrificed at 4 weeks after transplantation of bone marrow mesenchymal stem cells. The terminal deoxynucleotide transferase-mediated TUNEL method was used to detect the cardiomyocyte apoptosis index. Immunohistochemical method was used to detect the expression of BrdU positive stem cells and myocardial Foxcl and Oct4 proteins. The expression of Foxc1 mRNA and Oct 4 mRNA was detected by PCR technology. Experimental animals were purchased from the Experimental Animal Center of out hospital. This study has been reviewed by the Medical Ethics Society of our hospital.

\subsection{Establish a model of myocardial infarction}

Rats in the AMI and BMSCs groups were anesthetized with $10 \%$ chloral hydrate. Prepare the skin on the left front chest and fix the rat supine position on the operating table. Tracing the standard limb lead electrocardiogram according to the literature description. Under the action of the tracheal intubation guide lamp, the tracheal intubation is externally connected to a small animal ventilator, and the frequency is set at 90 times $/ \mathrm{min}$. Ensure that the effective ventilation per minute is $1.0 \mathrm{ml} / \mathrm{g}$. Sterilize the skin twice with $1 \%$ vitality iodine and lay a towel. Select the $3 \mathrm{rd}$ and 4 th intercostal space on the left chest for surgical incision, the incision is about $25 \mathrm{~cm}$ long, cut under the skin, and separate the muscles. At the same time, retract the lung lobe to the posterolateral side. After seeing the pericardium and cutting it, the heart can be exposed.

The left anterior descending branch of the left coronary artery at 1-2 mm below the right margin of the left atrial appendage and the left myocardium superficial layer of the pulmonary artery cone was ligated with 6.0 non-invasive silk thread. It was observed that the anterior wall of the left ventricle turned pale and contractility decreased. Electrocardiogram lead I showed ST-T immediately arched upward, and myocardial infarction model was established. Suture with No. 0 silk thread to close the chest cavity. After the spontaneous breathing of the rats recovered, the trachea cannula was removed and moved to a clean animal room for resuscitation. Postoperative intramuscular injection of penicillin $100,000 \mu / \mathrm{kg}$ to prevent infection.

\subsection{BMSCs transplantation}

One day before the transplantation of BMSCs, Brdu solution was added to the medium to make a mark. Under direct vision, the BMSCs group was divided into 4 points around the non-infarcted myocardium, and the BMSCs suspension was injected into the epicardium with a micro syringe at $100 \mu \mathrm{L}$ per point. The injection showed local cumulus-like edema as a success. The control group and AMI group were injected with equal volume of normal saline in the same way. Close the chest after the circulation has stabilized. After the rats recovered from spontaneous breathing, they gradually got rid of the ventilator, pulled out the tracheal intubation, and returned to the clean animal room to continue breeding. Penicillin is injected subcutaneously to prevent infection.

\subsection{Processing and pathological analysis of cardiac specimens}

At 4 weeks of the experiment, the rats were weighed and anesthetized with $10 \%$ chloral hydrate and fixed in a supine position. Through the midline incision of the neck, the right jugular vein was separated, and the jugular vein was punctured under direct vision, and $2-3 \mathrm{ml}$ of $10 \%$ potassium chloride was injected to stop the heart from beating at the end of diastole. Quickly open the rib cage, remove the heart, cut off the left and right atrial appendages and the remaining large blood vessels and rinse with ice saline repeatedly. Wash off the blood and blot it dry with filter paper. Transect the heart into two parts at approximately the level of the papillary muscle of the heart. The non-infarcted area near the apex of the heart was fixed with $10 \%$ formaldehyde solution for 12 hours for immunohistochemical staining and TUNEL detection. By overexpressing and silencing the target gene implanted into BMSC, and then grouping the cells to detect the apoptosis of rat cardiomyocytes.

\subsection{Immunohistochemical staining for the expression of Foxc1 and Oct4 in non-infarcted myocardium}

The specific steps are as follows. Anti-slipping treatment After the slides are scrubbed with detergent, rinse with running water. After immersing in sulfuric acid for 1 day, rinse with running water and bake dry. Soak in 95\% alcohol solution for 12 hours and bake dry. Soak in polylysine, bake dry, keep in the refrigerator at $4^{\circ} \mathrm{C}$ for future use. Routine dewaxing and gradient alcohol dehydration. The citric acid buffer was microwave repaired for 10 minutes, and after cooling, soaked in PBS for 3 times * 5 minutes. 3\% $\mathrm{H} 2 \mathrm{O} 2$ was added dropwise on TMA to remove endogenous peroxidase. After being left at room temperature for 20 minutes, PBS solution was soaked 3 times for 5 minutes. The slides were immersed in the antigen repair solution with $\mathrm{Ph}=$ 6.0 , heated in a microwave oven $\left(98-100^{\circ} \mathrm{C}, 2\right.$ times $* 7$ minutes) for antigen repair. After cooling, the PBS solution was soaked 3 times ${ }^{*} 5$ minutes. $20 \%$ normal goat serum blocking solution was added dropwise. After incubating at room temperature for 20 minutes, the endogenous biotin was blocked to discard the serum and do not wash. Diluted (1:100) good primary antibody (rabbit anti-rat Foxc1 or Oct4 polyclonal antibody) working solution was added dropwise. After $4^{\circ} \mathrm{C}$ refrigerator overnight, the temperature was re-warmed at $37^{\circ} \mathrm{C}$ for $45 \mathrm{~min}$. Soak in PBS for 3 times ${ }^{*} 5$ minutes. Add the biomarker secondary antibody dropwise, incubate at room temperature for 30 minutes, and soak in PBS for 3 times * 5 minutes. Add 1:200 diluted horseradish enzyme-labeled streptavidin (reagent D), incubate at room temperature for 30 minutes, and soak in PBS for 3 times * 5 minutes. The color of diaminobenzidine (DAB) was observed under a microscope. The reaction was terminated in a timely manner and rinsed with tap water for 10 minutes. Hematoxylin was counterstained for 1 minute, hydrochloric acid and alcohol 
were differentiated for 5 seconds, and rinsed under running water. Gradient alcohol dehydration, xylene transparent, neutral gum sealing, observed under a microscope.

Determination of test results: The cells with positive expression of Foxc1 and Oct4 showed brown, yellow and light yellow in the cytoplasm or nucleus under light microscope, and the intensity was strong positive, positive and weak positive respectively. Using IMAGE. Pro plus5.0 graphic analysis software, randomly selected 5 high power fields $\left({ }^{\star} 400\right)$ in the stained area, and determined the average integrated optical density (OD) of positive staining in each field. The German Lecia photomicrography system was used for image acquisition.

\subsection{Statistical analysis}

The data of this experiment are analyzed by the statistical 21.0 software, and the measurement data are expressed by the mean \pm standard deviation. The comparison between the means of each group adopts homogeneity test of variance and one-way analysis of variance. The correlation between the two indicators was analyzed using Pearson's linear correlation analysis, and the test level was $\alpha=0.05 . P<0.05$ considered the difference to be statistically significant.

\section{Results}

\subsection{Brdu-labeled BMSCs immunohistochemical results}

Four weeks after transplanting BMSCs into rats, the immunohistochemical staining of labeled BMSCs showed that the nuclei of positive cells in myocardial tissue located in the non-infarct area were stained brown (see Figure 1). The BMSCs marked by Brdu are indicated by an arrow in Figure 1.

\subsection{Apoptosis of rat cardiomyocytes}

By TUNEL method, the results of the study showed that the normal cardiomyocyte nuclei were blue, while the apoptosispositive cardiomyocyte nuclei were tan. The results of the study showed that the control group basically had no cardiomyocyte apoptosis, while the number of positive cells in the AMI group was significantly higher than that in the BMSCs group. The apoptosis index was calculated as the ratio of the number of positive cells to the total number of cardiomyocytes. The apoptosis indexes of AMI group and BMSCs group were $0.67 \pm 0.14$ and $0.31 \pm$ 0.12 , respectively, and the difference between the two groups was statistically significant $(P<0.05)$.

\subsection{Expression of Foxc1 and Oct4 protein in myocardium of non-infarct area in rats}

At 4 weeks after stem cell transplantation, immunohistochemical sections showed that the positively stained cells in the noninfarct area were brown-yellow under high magnification $\left({ }^{*} 400\right)$. The OD value of Foxc1 protein in BMSCs group was higher than that in AMI group (Table 1), the difference was statistically significant $(t=28.828, P<0.05)$. The OD value of Oct 4 protein in BMSCs group was higher than that in AMI group (Table 1), the difference was statistically significant $(t=25.842, P<0.05)$.

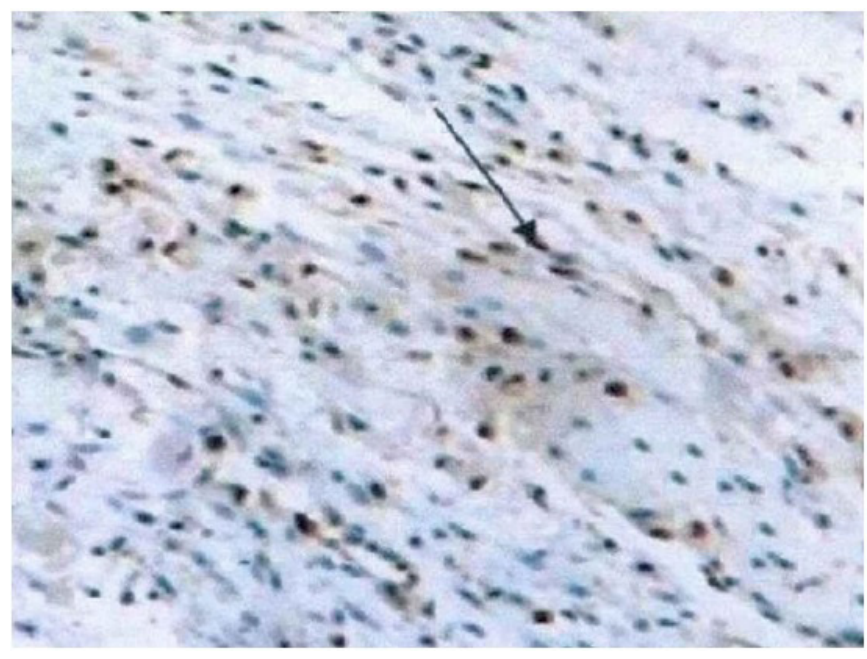

Figure 1. Brdu immunohistochemical staining 4 weeks after BMSCs transplantation $\left({ }^{*} 400\right)$.

Table 1. Expression of Foxc1 and Oct4 in non-infarcted myocardium of each group $(\mathrm{M} \pm \mathrm{SD}$, OD value).

\begin{tabular}{ccccc}
\hline Index & $\begin{array}{c}\text { AMI group } \\
(\mathrm{n}=60)\end{array}$ & $\begin{array}{c}\text { BMSCs group } \\
(\mathrm{n}=60)\end{array}$ & $t$ & $P$ \\
\hline Foxc1 & $0.19 \pm 0.07$ & $0.74 \pm 0.13$ & 28.828 & $<0.001$ \\
Oct4 & $0.18 \pm 0.06$ & $0.55 \pm 0.09$ & 25.842 & $<0.001$ \\
\hline
\end{tabular}

\section{Discussion}

Apoptosis refers to the autonomous and orderly death of cells controlled by genes in order to maintain the stability of the internal environment (Xiong et al., 2020; Hoque et al., 2019). Apoptosis is different from cell necrosis. Apoptosis is an active process, it involves the activation, expression and regulation of a series of genes (Sukanya et al., 2018). It is not a phenomenon of self-injury under pathological conditions, and is a process of death that we actively strive to better adapt to the living environment (Hussien et al., 2017). Apoptosis is regulated by intracellular genes. Under physiological conditions, pro-apoptotic factors and inhibitors in the body have the same effect to maintain the body's balance.

When the relative amount of pro-apoptotic factors is less than the relative amount of inhibitory factors, cells appear to proliferate, such as tumors and autoimmune diseases (Zheng et al., 2020; Li et al., 2015). Conversely, the cells exhibit apoptosis and damaged tissue cannot be repaired, such as AMI. In recent years, cardiomyocyte apoptosis has become a research hotspot in cardiovascular diseases (Eldin et al., 2019; Xie et al., 2019; Khanabdali et al., 2015). Apoptosis occurs in AMI, which mainly exists in non-infarcted myocardial tissue, and there are also a small part of myocardial apoptotic cells in the infarct (Cao et al., 2019). After AMI, apoptotic cells and necrotic cells are replaced by fibroblasts, and ventricular remodeling occurs.

Apoptosis is a kind of programmed death caused by various genes, and is a form of cell death (Zhou et al., 2019). Apoptosis participates in the growth and development of tissues and maintains 
a stable internal environment. The process of apoptosis is the accumulation of chromatin, and the cytoplasm is concentrated to form apoptotic bodies, which are quickly engulfed by surrounding cells. Excessive apoptosis is involved in certain diseases, such as AMI (Wang et al., 2015). In this study, the TUNEL method was used to detect cardiomyocyte apoptosis. The control group basically had no cardiomyocyte apoptosis, the AMI group had a large amount of cardiomyocyte apoptosis in the non-infarct area, and the BMSCs group had more cardiomyocyte apoptosis. The apoptosis index of AMI group was greater than that of BMSCs group, and the difference was statistically significant $(P<0.05)$. The results suggest that cardiomyocyte apoptosis is involved in the occurrence and development of myocardial infarction. Therefore, cardiomyocyte apoptosis is one of the forms that cause myocardial infarction cell damage. After transplantation, BMSCs reach the heart and interact with rat cardiomyocytes and extracellular matrix. In addition, it exerts its differentiation potential and differentiates into cardiomyocytes specifically in non-infarcted areas to replace damaged cells.

The progressive loss of cardiomyocytes caused by increased cardiomyocyte apoptosis after AMI is one of the main causes of congestive heart failure after AMI (Cao et al., 2019). Bone marrow stem cells are injected into the myocardial infarction area, and the planted bone marrow stem cells can differentiate into cardiomyocytes and endothelial cells in the injured area. In turn, it promotes local neovascularization, inhibits cardiomyocyte apoptosis, and increases the number of effectively contracted cardiomyocytes. And restore the myocardial contractility, thereby improving cardiac function. In addition to direct differentiation into vascular endothelial cells, stem cells can also secrete factors such as vascular endothelial growth factor, promote angiogenesis, and improve ischemic conditions (Al-Qadhi et al., 2020; Grom et al., 2020; Barros et al., 2021). Thereby reducing the degree of apoptosis in non-infarct area. Cardiomyocytes differentiated by BMSCs at the site of myocardial injury can establish an effective electro-mechanical coupling with normal cardiomyocytes to make the heart contraction more coordinated.

In this experiment, immunohistochemical examination and image analysis were used to find that Foxcl and Oct4 were rarely expressed in normal rat myocardial tissue. Foxcl and Oct 4 are mostly expressed in non-infarcted myocardial tissue, suggesting that Foxc1 and Oct4 are jointly involved in the process of cardiomyocyte apoptosis after AMI (Zhang et al., 2019; Zhang et al., 2017; Yu et al., 2013). Four weeks after BMSCs transplantation, the OD values of Foxc1 and Oct4 protein in AMI group were significantly lower than those in BMSCs group, and the difference was statistically significant $(P<0.05)$. The results showed that the transplantation of BMSCs inhibited the expression of Foxcl and Oct4 proteins, while enhancing the anti-apoptotic effect. And also found in the cardiomyocyte apoptosis pictures detected by TUNEL method, the number of apoptotic cells in the BMSCs group was significantly less than the AMI group, and the apoptosis index was significantly lower than the AMI group.

4 weeks after transplantation of BMSCs can reduce cardiomyocyte apoptosis after acute myocardial infarction in rats. The mechanism of its action may be related to its up- regulation of Oct4 protein expression and Foxc1 protein and mRNA expression. Thereby inhibiting cardiomyocyte apoptosis and improving the function of the heart, while improving the prognosis of AMI.

\section{References}

Al-Qadhi, G., Soliman, M., Abou-Shady, I., \& Rashed, L. (2020). Gingival mesenchymal stem cells as an alternative source to bone marrow mesenchymal stem cells in regeneration of bone defects: in vivo study. Tissue \& Cell, 63, 101325. http://dx.doi.org/10.1016/j. tice.2019.101325. PMid:32223954.

Barros, C. P., Grom, L. C., Guimarães, J. T., Balthazar, C. F., Rocha, R. S., Silva, R., Almada, C. N., Pimentel, T. C., Venâncio, E. L., Collopy, I. Jr., Maciel, P. M. C., Freitas, M. Q., Esmerino, E. A., Silva, M. C., Duarte, M. C. K. H., Sant'Ana, A. S., \& Cruz, A. G. (2021). Paraprobiotic obtained by ohmic heating added in whey-grape juice drink is effective to control postprandial glycemia in healthy adults. Food Research International, 140, 109905. http://dx.doi.org/10.1016/j. foodres.2020.109905. PMid:33648206.

Cao, M., Yu, C., Yao, Z., Gao, X., \& Wu, S. (2019). Atractylodesin III maintains mitochondrial function and inhibits caspase- 3 activity to reverse apoptosis of cardiomyocytes in AMI rats. International Journal of Clinical and Experimental Pathology, 12(1), 198-204. PMid:31933734.

Chen, Q., Zhang, Y., Zhu, H., Yuan, X., Luo, X., Wu, X., Chen, S., Chen, Y., Xu, J., Issa, H. A., Zheng, Z., Hu, J., \& Yang, T. (2020). Bone marrow mesenchymal stem cells alleviate the daunorubicin-induced subacute myocardial injury in rats through inhibiting infiltration of T lymphocytes and antigen-presenting cells. Biomedicine and Pharmacotherapy, 121, 109157. http://dx.doi.org/10.1016/j. biopha.2019.109157. PMid:31731195.

Dey, D., Jingar, P., Agrawal, S., Shrivastava, V., Bhattacharya, A., Manhas, J., Garg, B., Ansari, M. T., Mridha, A. R., Sreenivas, V., Khurana, A., \& Sen, S. (2020). Symphytum officinale augments osteogenesis in human bone marrow-derived mesenchymal stem cells in vitro as they differentiate into osteoblasts. Journal of Ethnopharmacology, 248, 112329. http://dx.doi.org/10.1016/j.jep.2019.112329. PMid:31672526.

Dudhia, J., Becerra, P., Valdés, M. A., Neves, F., Hartman, N. G., \& Smith, R. K. (2015). In vivo imaging and tracking of technetium$99 \mathrm{~m}$ labeled bone marrow mesenchymal stem cells in equine tendinopathy. Journal of Visualized Experiments, (106), e52748. http://dx.doi.org/10.3791/52748. PMid:26709915.

Eldin, H. E. M., Ibrahim, M. A. A., Mousa, A. M. I., Metwaly, H. G., \& Abo-Hassan, N. F. E. (2019). Cardiogenic Differentiation of Murine Bone Marrow-Derived Mesenchymal Stem Cells by 5-Azacytidine: a follow-up in vitro study. Journal of Microscopy Ultrastructure, 7(4), 185-193. http://dx.doi.org/10.4103/JMAU.JMAU_17_19. PMid:31803573.

Fujimori, K., Iguchi, Y., Yamashita, Y., Gohda, K., \& Teno, N. (2019). Synthesis of novel farnesoid $\mathrm{x}$ receptor agonists and validation of their efficacy in activating differentiation of mouse bone marrowderived mesenchymal stem cells into osteoblasts. Molucules, 24(22), 4155. PMid:31744088. http://dx.doi.org/10.3390/molecules24224155.

Grom, L. C., Rocha, R. S., Balthazar, C. F., Guimarães, J. T., Coutinho, N. M., Barros, C. P., Pimentel, T. C., Venâncio, E. L., Collopy, I. Jr., Maciel, P. M. C., Silva, P. H. F., Granato, D., Freitas, M. Q., Esmerino, E. A., Silva, M. C., \& Cruz, A. G. (2020). Postprandial glycemia in healthy subjects: which probiotic dairy food is more adequate? Journal of Dairy Science, 103(2), 1110-1119. PMid:31785881. http:// dx.doi.org/10.3168/jds.2019-17401. 
Hoque, M. M., Lee, Y. E., Kim, H. R., \& Shin, M. G. (2019). Potential biomarkers and antagonists for fluoranthene-induced cellular toxicity of bone marrow derived mesenchymal stem cells. Blood Research, 54(4), 253-261. http://dx.doi.org/10.5045/br.2019.54.4.253. PMid:31915651.

Hussien, N. I., Ebrahim, N., Mohammed, O. M., \& Sabry, D. (2017). Combination of obestatin and bone marrow mesenchymal stem cells prevents aggravation of endocrine pancreatic damage in type II diabetic rats. International Journal of Stem Cells, 10(2), 129-143. http://dx.doi.org/10.15283/ijsc17035. PMid:29186652.

Kamm, J. L., Parlane, N. A., Riley, C. B., Gee, E. K., Dittmer, K. E., \& McIlwraith, C. W. (2019). Blood type and breed-associated differences in cell marker expression on equine bone marrowderived mesenchymal stem cells including major histocompatibility complex class II antigen expression. PLoS One, 14(11), e0225161. http://dx.doi.org/10.1371/journal.pone.0225161. PMid:31747418.

Khanabdali, R., Saadat, A., Fazilah, M., Bazli, K. F., Qazi, R. E., Khalid, R. S., Hasan Adli, D. S., Moghadamtousi, S. Z., Naeem, N., Khan, I., Salim, A., Shamsuddin, S. A., \& Mohan, G. (2015). Promoting effect of small molecules in cardiomyogenic and neurogenic differentiation of rat bone marrow-derived mesenchymal stem cells. Drug Design, Development and Therapy, 10, 81-91. PMid:26766903.

Li, X., Wang, J., Cao, J., Ma, L., \& Xu, J. (2015). Immunoregulation of bone marrow-derived mesenchymal stem cells on the chronic cigarette smoking-induced lung inflammation in rats. BioMed Research International, 2015, 932923. http://dx.doi.org/10.1155/2015/932923. PMid:26665150.

Lu, M., Xu, Y., Wang, M., Guo, T., Luo, F., Su, N., Wang, Z., Xu, L., \& Liu, Z. (2019). MicroRNA-23 inhibition protects the ischemia/reperfusion injury via inducing the differentiation of bone marrow mesenchymal stem cells into cardiomyocytes. International Journal of Clinical and Experimental Pathology, 12(3), 1060-1069. PMid:31933920.

Mahmoud, N. S., Ahmed, H. H., Mohamed, M. R., Amr, K. S., Aglan, H. A., Ali, M. A. M., \& Tantawy, M. A. (2020). Role of nanoparticles in osteogenic differentiation of bone marrow mesenchymal stem cells. Cytotechnology, 72(1), 1-22. http://dx.doi.org/10.1007/s10616019-00353-y. PMid:31722051.

Mahmoudian-Sani, M. R., Forouzanfar, F., Asgharzade, S., \& Ghorbani, N. (2019). Overexpression of MiR-183/96/182 triggers retina-like fate in human bone marrow-derived mesenchymal stem cells (hBMSCs) in culture. Journal of Ophthalmology, 2019, 2454362. http://dx.doi. org/10.1155/2019/2454362. PMid:31885884.

Majid, A. L., Ahmed, Z., \& Khan, R. (2020). Effect of pumpkin seed oil on cholesterol fractions and systolic/diastolic blood pressure. Food Science Technology, 40(3), 769-777. http://dx.doi.org/10.1590/fst.03720.

Mazdeh, D. Z., Mirshokraei, P., Emami, M., Mirshahi, A., \& Karimi, I. (2018). 17 $\beta$-estradiol improves the efficacy of exploited autologous bone marrow-derived mesenchymal stem cells in non-union radial defect healing: a rabbit model. Research in Veterinary Science, 118, 11-18. http://dx.doi.org/10.1016/j.rvsc.2017.12.024. PMid:29334646.

Omar, A. M., Meleis, A. E., Arfa, S. A., Zahran, N. M., \& Mehanna, R. A. (2019). Comparative study of the therapeutic potential of mesenchymal stem cells derived from adipose tissue and bone marrow on acute myocardial infarction model. Oman Medical Journal, 34(6), 534-543. http://dx.doi.org/10.5001/omj.2019.97. PMid:31745418.

Su, G., Liu, L., Yang, L., Mu, Y., \& Guan, L. (2017). Homing of endogenous bone marrow mesenchymal stem cells to rat infarcted myocardium via ultrasound-mediated recombinant SDF-1alpha adenovirus in microbubbles. Oncotarget, 9(1), 477-487. http://dx.doi.org/10.18632/ oncotarget.23068. PMid:29416629.
Sukanya, V. S., \& Mohanan, P. V. (2018). Degradation of Poly(epsiloncaprolactone) and bio-interactions with mouse bone marrow mesenchymal stem cells. Colloids and Surfaces B: Biointerfaces, 163, 107-118. http://dx.doi.org/10.1016/j.colsurfb.2017.12.039. PMid:29287231.

Sultan, M. T., Aslam, F., Rasool, B., Imran, M., Ahmad, A. N., Tariq, H. B., Afzal, M. I., Rehman, H., Shahbaz, M., \& Nadeem, M. (2021). Nigella sativa ameliorates oxidative stress induced adverse effects in rodent modeling studies: Indices of serum chemistry and hematology. Food Science Technology, 41(2), 404-411. http://dx.doi. org/10.1590/fst.01120.

Vidal, A. R., Cansian, R. L., Mello, R. O., Kubota, E. H., Demiate, L. M., Zielinski, A. A. F., \& Dornelles, R. C. P. (2020). Effect of ultrasound on the functional and structural properties of hydrolysates of different bovine collagens. Food Science Technology, 40(2), 347-353.

Wang, J., Li, C., Cao, Y., Wang, Q., Lu, L., Chang, H., Wu, Y., Han, J., Wang, W., Tu, P., \& Wang, Y. (2015). Mechanism of QSYQ on antiapoptosis mediated by different subtypes of cyclooxygenase in AMI induced heart failure rats. BMC Complementary and Alternative Medicine, 15(1), 352. http://dx.doi.org/10.1186/s12906-015-0869-z. PMid:26445960.

Wu, T., Xie, Y., Huang, J., Li, P., Wang, X., Yan, Y., Xia, T., Li, L., Zhu, F., Li, H., \& Wu, R. (2017). The optimal intervention time of bone marrow mesenchymal stem cells in ameliorating cardiac fibrosis induced by viral myocarditis: a randomized controlled trial in mice. Stem Cells International, 2017, 3258035. http://dx.doi. org/10.1155/2017/3258035. PMid:29362568.

Xie, D. M., Li, Y. L., Li, J., Li, Q., Lu, G., Zhai, Y., Zhang, J., Huang, Z., \& Gao, X. (2019). CD51 distinguishes a subpopulation of bone marrow mesenchymal stem cells with distinct migratory potential: a novel cell-based strategy to treat acute myocardial infarction in mice. Stem Cell Research \& Therapy, 10(1), 331. http://dx.doi. org/10.1186/s13287-019-1439-y. PMid:31747966.

Xiong, L., Sun, L., Zhang, Y., Peng, J., Yan, J., \& Liu, X. (2020). Exosomes from bone marrow mesenchymal stem cells can alleviate early brain injury after subarachnoid hemorrhage through miRNA1295p-HMGB1 pathway. Stem Cells and Development, 29(4), 212-221. http://dx.doi.org/10.1089/scd.2019.0206. PMid:31801411.

Xu, J. Y., Qian, H. Y., Huang, P. S., Xu, J., Xiong, Y. Y., Jiang, W. Y., Xu, Y., Leng, W. X., Li, X. D., Chen, G. H., Tang, R. J., Huang, C. R., Hu, M. J., Jin, C., Wu, Y., Zhang, J., Qian, J., Xu, B., Zhao, S. H., Lu, M. J., Shen, R., Fang, W., Wu, W. C., Chen, X., Wang, Y., Li, W., Lu, X. F., Jiang, X. F., Ma, C. C., Li, J. W., Geng, Y. J., Qiao, S. B., Gao, R. L., \& Yang, Y. J. (2019). Transplantation efficacy of autologous bone marrow mesenchymal stem cells combined with atorvastatin for acute myocardial infarction (TEAM-AMI): rationale and design of a randomized, double-blind, placebo-controlled, multi-center, Phase II TEAM-AMI trial. Regenerative Medicine, 14(12), 10771087. http://dx.doi.org/10.2217/rme-2019-0024. PMid:31829095.

Yamada, Y., Nakamura-Yamada, S., Umemura-Kubota, E., \& Baba, S. (2019). Diagnostic cytokines and comparative analysis secreted from exfoliated deciduous teeth, dental pulp, and bone marrow derived mesenchymal stem cells for functional cell-based therapy. International Journal of Molecular Sciences, 20(23), 5900. http:// dx.doi.org/10.3390/ijms20235900. PMid:31771293.

Yu, C. W., Choi, S. C., Hong, S. J., Choi, J. H., Park, C. Y., Kim, J. H., Park, J. H., Ahn, C. M., \& Lim, D. S. (2013). Cardiovascular event rates in patients with ST-elevation myocardial infarction were lower with early increases in mobilization of Oct4(high)Nanog(high) stem cells into the peripheral circulation during a 4-year follow-up. International Journal of Cardiology, 168(3), 2533-2539. http://dx.doi. org/10.1016/j.ijcard.2013.03.060. PMid:23602281. 
Zhang, G. W., Gu, T. X., Guan, X. Y., Sun, X. J., Qi, X., Li, X. Y., Wang, X. B., Yu, L., Jiang, D. Q., Tang, R., \& Li-Ling, J. (2015). bFGF binding cardiac extracellular matrix promotes the repair potential of bone marrow mesenchymal stem cells in a rabbit model for acute myocardial infarction. Biomedical Materials, 10(6), 065018. http:// dx.doi.org/10.1088/1748-6041/10/6/065018. PMid:26657457.

Zhang, S. P., Yang, R. H., Shang, J., Gao, T., Wang, R., Peng, X. D., Miao, X., Pan, L., Yuan, W. J., Lin, L., \& Hu, Q. K. (2019). FOXC1 up-regulates the expression of toll-like receptors in myocardial ischaemia. Journal of Cellular and Molecular Medicine, 23(11), 7566-7580. http://dx.doi.org/10.1111/jcmm.14626. PMid:31517441.

Zhang, S., Zhao, L., Wang, J., Chen, N., Yan, J., \& Pan, X. (2017). HIF-2a and Oct 4 have synergistic effects on survival and myocardial repair of very small embryonic-like mesenchymal stem cells in infarcted hearts. Cell Death \& Disease, 8(1), e2548. http://dx.doi.org/10.1038/ cddis.2016.480. PMid:28079892.

Zheng, J., Zhu, L., In, L. L., Chen, Y., Jia, N., \& Zhu, W. (2020). Bone marrow-derived mesenchymal stem cells-secreted exosomal microRNA-192-5p delays inflammatory response in rheumatoid arthritis. International Immunopharmacology, 78, 105985. http:// dx.doi.org/10.1016/j.intimp.2019.105985. PMid:31776092.

Zhou, L., Liu, S., Wang, Z., Yao, J., Cao, W., Chen, S., Xie, W., Feng, S., Xu, Y., Cheng, T., Han, M., \& Feng, S. (2019). Bone marrow-derived mesenchymal stem cells modified with Akt1 ameliorates acute liver GVHD. Biological Procedures Online, 21(1), 24. http://dx.doi. org/10.1186/s12575-019-0112-2. PMid:31889917. 